\title{
Cross-Cultural Differences in Cognitive Style, Individualism/Collectivism and Map Reading between Central European and East Asian University Students
}

\author{
David Lacko ${ }^{1,2}$, Čeněk Šašinka², Jiří Čeněk ${ }^{2,3}$, Zdeněk Stachoň ${ }^{2}$, Wei-lun Lu² \\ ${ }^{1}$ Department of Psychology, Faculty of Arts, Masaryk University, Arna Nováka 1/1, 60200 Brno, Czech Republic \\ ${ }^{2}$ The Division of Information and Library Studies, Faculty of Arts, Masaryk University, Arna Nováka 1/1, 60200 \\ Brno, Czech Republic \\ ${ }^{3}$ Department of Social Development, Faculty of Regional Development and International Studies, Mendel University, \\ třída Generála Píky 2005/7, 61300 Brno, Czech Republic
}

The article examines cross-cultural differences encountered in the cognitive processing of specific cartographic stimuli. We conducted a comparative experimental study on 98 participants from two different cultures, the first group comprising Czechs $(N=53)$ and the second group comprising Chinese $(N=$ 22) and Taiwanese $(N=23)$. The findings suggested that the Central European participants were less collectivistic, used similar cognitive style and categorized multivariate point symbols on a map more analytically than the Asian participants. The findings indicated that culture indeed influenced human perception and cognition of spatial information. The entire research model was also verified at an individual level through structural equation modelling (SEM). Path analysis suggested that individualism and collectivism was a weak predictor of the analytic/holistic cognitive style. Path analysis also showed that cognitive style considerably predicted categorization in map point symbols.

Key words: cognitive style, cross-cultural differences, categorization, individualism/collectivism, analytic/ holistic

\section{Introduction}

The objectives of the study were 1) to explore the cross-cultural differences between Central European and East Asian populations at three distinct levels and 2) to examine how these levels were connected. The presented research examined whether the selected populations differed in the degree of individualism/collectivism and the cognitive style measured by the Compound Figure Test
(CFT), and whether cultural differences manifested during cartographic task solving, specifically in the categorization of multivariate point symbols.

The theory of analytic and holistic $(\mathrm{A} / \mathrm{H}) \mathrm{cog}$ nition postulates the existence of distinct cognitive and perceptual styles - relatively stable ways of cognitive processing (for review, see Masuda, 2017; Nisbett \& Masuda, 2003; Nisbett \& Miyamoto, 2005; Nisbett, Peng, Choi, \& Norenzayan, 2001). The majority of research in this field focuses on comparing the charac-

Correspondence concerning this article should be addressed to David Lacko, Department of Psychology, Faculty of Arts, Masaryk University, Arna Nováka 1/1, 60200 Brno, Czech Republic. E-mail: david.lacko@mail.muni.cz

ORCID https://orcid.org/0000-0002-2904-8118

Received March 21, 2019

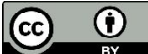


teristics of cognitive processes in two world regions: the "West" (e.g., North America, Western Europe) and the "East" (mainly the countries of East and Southeast Asia such as China, Japan, South Korea, etc.; Nisbett, 2003). The theory of $\mathrm{A} / \mathrm{H}$ cognitive style assumes that Westerners adopt relatively more analytic cognitive style and East Asians the holistic one. $\mathrm{A} / \mathrm{H}$ cognitive style is defined as "the tendency for individuals to process information either as an integrated whole or in discrete parts of that whole" (Graff, 2003, p. 21). Although the primary focus of the theory is the comparison of cognitive processes among cultures, it does not rule out the existence of within-culture individual differences in these processes. In other words, if we compare two people from a certain cultural background, one can perceive relatively more analytically, while the other perceives more holistically.

The $\mathrm{A} / \mathrm{H}$ model is based on the classic Witkin's model of field dependent/independent cognition (Witkin, Moore, Goodenough, \& Cox, 1977 ) and the Gestalt principles of perceptual grouping and figure-ground organization (Wagemans et al., 2012). Recent findings suggest that many differences exist among people in higher cognitive processes, such as categorization, classification, decision-making, reasoning and causal attribution, and the lower perceptual processes related to attention, such as detection of change and field dependence (for review, see Nisbett et al., 2001; Nisbett \& Masuda, 2003; Nisbett \& Miyamoto, 2005). More precisely, people perceiving relatively more analytically tend to focus more on perceptually salient (focal) objects and less on background and contextual information, and on the relationships between objects in the perceptual field (Chua, Boland, \& Nisbett, 2005; Masuda \& Nisbett, 2001; Nisbet \& Masuda, 2003). Furthermore, people perceiving relatively more analytically are also less dependent on external reference frameworks than their holistic counterparts (Ji, Peng, \& Nisbett, 2000; Kitayama, Duffy, Kawamura, \& Larsen, 2003), and are less sensitive to contextual changes while being more sensitive to changes in focal objects (Masuda \& Nisbett,
2006). Researchers believe that cognitive style also affects the processes of categorization and classification. Whereas analytic individuals categorize objects by applying formal rules of reasoning, holistic individuals categorize objects by their overall (or holistic) qualities, similarity and mutual relationships (Chiu, 1972; Ji, Zhang, \& Nisbett, 2004; Norenzayan, Smith, Kim, \& Nisbett, 2002).

The value dimension of individualism and collectivism $(\mathrm{I} / \mathrm{C})$ in cross-cultural research is commonly related to $\mathrm{A} / \mathrm{H}$ cognitive style and often used as a predictor of cognitive style and other psychological phenomena (for review, see Oyserman, Coon, \& Kemmelmeier, 2002). Some research suggested that collectivistic individuals are field dependent and holistic, whereas people from predominantly individualistic societies are field independent and analytic (Ji et al., 2000; Nisbett, 2003; Nisbett et al., 2001; Triandis \& Gelfand, 1998). However, the relationship between $\mathrm{I} / \mathrm{C}$ and $\mathrm{A} / \mathrm{H}$ cognitive styles is rarely measured at the individual level, and many authors have only assumed the aforementioned relationships. Other research has failed to find any empirical evidence at all of relationships at the individual level between I/C and A/H cognitive styles (e.g., Davidoff, Fonteneau, \& Fagot, 2008; McKone et al., 2010).

In the current literature though, theoretical considerations (e.g., Hermans \& Kempen, 1998; Matsumoto, 1999) and empirical evidence (e.g., Levine et al., 2003; Oyserman et al., 2002; Takano \& Osaka, 1999; Takano \& Osaka, 2018) can be found, criticizing this dichotomous approach as overly simplifying and reductionist. Post-communist European countries are significantly more holistic and collectivistic than Western Europe (Varnum, Grossmann, Katunar, Nisbett, \& Kitayama, 2008). Other findings suggest the existence of significant cultural differences not only across national borders (e.g., Federici, Stella, Dennis, \& Hündsfelt, 2011; Kitayama, Park, Sevincer, Karasawa, \& Uskul, 2009; Varnum et al., 2008) but also between people from different regions in a single country (e.g., Kitayama, Ishii, Imada, Takemura, \& Ramaswamy, 2006; Knight \& 
Nisbett, 2007; Uskul, Kitayama, \& Nisbett, 2008).

These critical findings suggest that the dichotomous model of cognitive styles might be overly reductionist. An alternative model was proposed by Kozhevnikov, Evans, and Kosslyn (2014). Their model is based on an older model by Nosal (1990). It emphasizes the ecological nature of cognitive style that is viewed as a pattern of cognitive adaptation to the environment. Cognitive style is in this model environmentally dependent, flexible and task specific. This model is hierarchical in the form of a cognitive-style matrix organizing cognitive styles on two axes: a) levels of information processing (perception, concept formation, higher-order processing, metacognitive processing), and b) cognitive style families (context dependence and independence, rulebased and intuitive processing, internal and external locus, integration and compartmentalization). According to this model, various components of cognitive style would not have to be inevitably (cor)related - a specific environment could, for example, elicit development of local processing (analytic characteristic) and focus on holistic regions of the map (holistic characteristic). This theoretical model might explain the absence of correlations between various facets of cognitive style reported in some studies (e.g., Hakim, Simons, Zhao, \& Wan, 2017; Kster, Castel, Gruber, \& Kärtner, 2017).

It should be noted that the number of empirical studies that extend beyond the East-West dichotomy and explore the nature of cognitive style and related factors in other cultural regions, such as Central Europe, is rather limited (with the exception of, for example, Cieślikowska, 2006; Čeněk, 2015; Kolman, Noorderhaven, Hofstede, \& Dienes, 2003; Stachoň et al., 2018; Varnum et al., 2008). The current research suggests that the people of Central Europe are rather moderately analytical in cognitive style and relatively, although not extremely, individualistic.

As mentioned above, the study employed cartographic tasks and stimuli in order to explore the manifestation of cognitive style. This follows research that has evaluated cartographic visualization methods that began with the publication The Look of Maps (Robinson, 1952). These methods gradually developed into the complex field of cognitive cartography. Subsequent to cognitive cartography, mappsychology research was later introduced by Montello (2002). This approach uses maps as stimuli in order to understand human perception and cognition. Examples of map-psychology research include studies on the influence of alignment and rotation on memory (Tversky, 1981) and the influence of cognitive style while working with bivariate risk maps (Šašinka et al., 2018). Categorization in cartographic stimuli was part of the work of Lewandowski et al. (1993), and research conducted around the same time anticipated cross-cultural differences in map reading (e.g., MacEachren, 1995; Wood, 1984) that was ultimately observed (e.g., Angsüsser, 2014; Stachoň et al., 2018; Stachoň et al., 2019). From the cross-cultural perspective, especially in $\mathrm{A} / \mathrm{H}$ theory, a most interesting study was conducted by McCleary (1975), who examined the categorization of map point symbols. The author found differences in the clustering of dot symbols and identified two user groups from these findings: atomists and generalists, who analogously correspond to the concept of $\mathrm{A} / \mathrm{H}$ cognitive style. Nevertheless, another study (Sadahiro, 1997) did not confirm this grouping, even though the author also discovered individual differences in the clustering of dot symbols in maps (cf. Sadahiro, 1997).

Consequently, the objective of this research was to further investigate the nature and manifestation of cognitive style in relation to variables such as individualism/collectivism in the culture of Central Europe (Czechia), compared to typical Eastern Asian cultures (China and Taiwan) - specifically, 1) to analyze cross-cultural differences between these two samples in $1 / C$, visual perception (global versus local distribution of attention) and categorization (clustering) in map stimuli, and 2) to verify the entire theoretical model of relationships between $\mathrm{I} / \mathrm{C}$ and $\mathrm{A} / \mathrm{H}$ cognitive styles at an individual level and estimate the relationship be- 


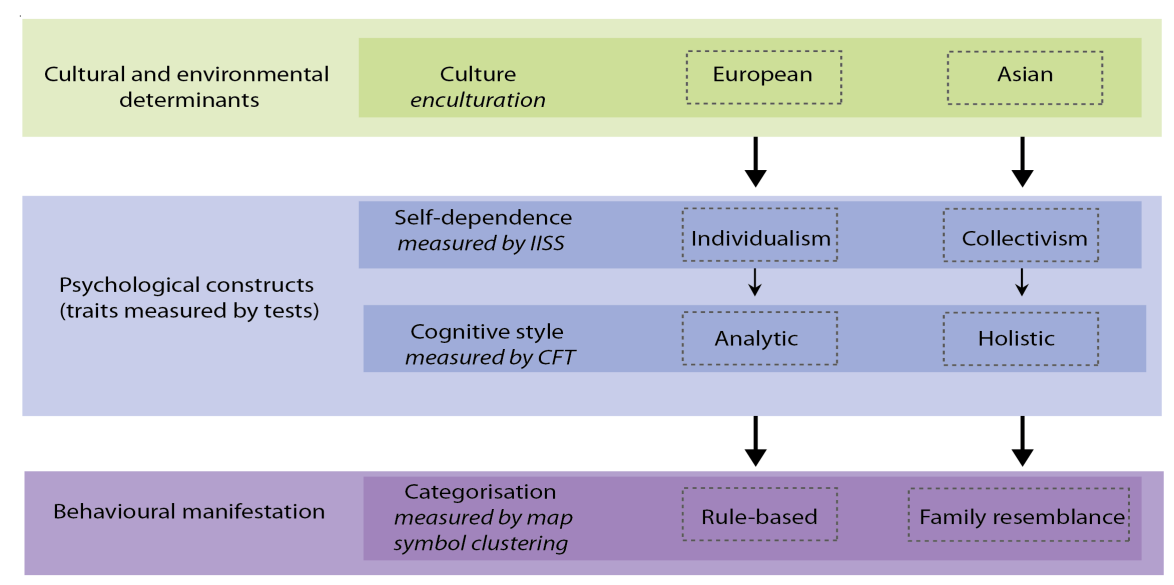

Figure 1 Research model

tween $\mathrm{I} / \mathrm{C}$ and selected manifestations of $\mathrm{A} / \mathrm{H}$ cognitive style (global/local attention) and map reading (categorization; see Figure 1).

\section{Methods and Procedures}

To achieve the above-mentioned objectives, we applied several methods (described in detail below) using Hypothesis online testing platform (see Procedure section). We also collected sociodemographic information such as age, gender, socioeconomic status (SES), cartography skills, eye defects, number of siblings, etc.

\section{Independent and Interdependent Self Scale}

To measure the individual-level I/C, we administered the IISS - Independent and Interdependent Self Scale (Lu \& Gilmour, 2007). The IISS is derived from the CSC - Self-Construal Scale (Singelis, 1994), the Individualism-Collectivism Scale (Triandis \& Gelfand, 1998) and the concept of independent/interdependent self-construal (Markus \& Kitayama, 1991). The IISS comprises 42 (21 for the Independent and 21 for Interdependent Self-Construal Scale) seven-point Likert-type numerical items (1 = strongly disagree, 7 = strongly agree). The original version of the questionnaire was administered in simplified Chinese ( $\mathrm{Lu} \&$ Gilmour, 2007). It contains items such as "I believe that people should try hard to satisfy their interests." (independent subscale) or "I believe that family is the source of our self." (interdependent subscale). The Czech version of the questionnaire was translated from English in parallel by three independent translators. Europeans should have higher independent self-construal (individualistic), and East Asians should be more interdependent (collectivistic; Markus \& Kitayama, 1991).

\section{Compound Figure Test}

The perceptual factors of cognitive style, more specifically the global and local distribution of attention, were measured using the CFT Compound Figure Test, which is a modified version of the Navon method (Navon, 1977) and has been previously used in several studies (e.g., Kukaňová, 2017; Opach et al., 2018; Šašinka et al., 2018). The CFT comprises six practice trials and 32 test trials (blocked design, same 16 trials for both local and global processing). Number of trials was considered satisfactory based on previous research (Davidoff et al., 2008; von Mühlenen, Bellaera, 
Singh, \& Srinivasa, 2018). Each trial involves presenting one "Navon figure" - a large number composed of copies of a smaller different number (Figure 2). In the local trial, participants were asked to identify the small numbers as quickly as possible. In the global trial, they were required to identify the large number. Participants used computer mouse to respond. Reaction time and correct identification were measured in each trial. The average reaction time and average success rate was calculated separately for the local (local reaction time, indicating analytic processing) and global (global reaction time, indicating holistic processing) trials.

The main output of the CFT is the global precedence score, which is computed as the difference between the absolute global and local reaction times (e.g., Gerlach \& Poirel, 2018; McKone et al., 2010). High values of the global precedence score indicate a holistic cognitive style (global precedence), low or even negative values indicate an analytic cognitive style (local precedence). According to previous research, people should generally perceive global features more quickly than local features (Navon, 1977). Furthermore, analytic perceiv-
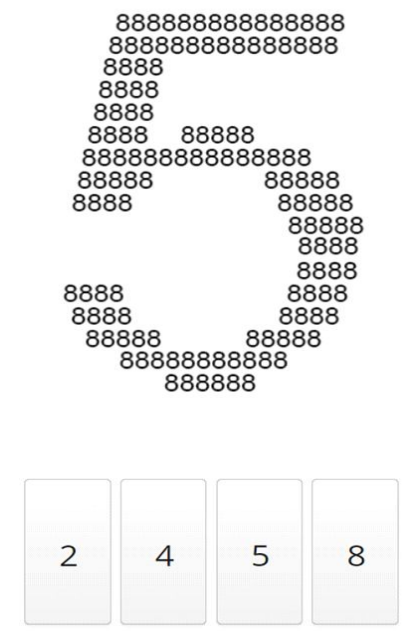

Figure 2 Example of the Navon figure used in the CFT ers should be relatively quicker in local and relatively slower in global tasks than holistic perceivers (Peterson \& Deary, 2006).

\section{Categorization of Multivariate Map Symbols}

Map reading and understanding is considered as a part of visual literacy (Peña, 2017). In addition, the maps represent the complex stimuli, which enable the user not only to understand the presented information but also to derive the additional information (Morita, 2004), therefore we used the cartographic stimuli. The cartographic visualization of multiple phenomena is known as multivariate mapping. Multivariate point symbols are one possible multivariate mapping method (Slocum, McMaster, Kessler, \& Howard, 2005). We created specific cartographic tasks for purposes of our experiment. Categorization was measured with CMMS - Categorization of Multivariate Map Symbols, which is based on previous research in categorization (Chiu, 1972; Ji et al., 2004; Norenzayan et al., 2002) and on the relationship between cognitive style and map reading (e.g., Herman et al., 2019; Kubíček et al., 2016; Opach, Popelka, Doležalová, \& Rod, 2018; Stachoň et al., 2018; Šašinka et al., 2018). The CMMS measures a specific component of categorization, namely clustering (cf. McCleary, 1975; Sadahiro, 1997).

The method comprised three practice trials and twenty test trials. The administration took between 15 and 30 minutes. In each trial, a fictional map comprising multiple territorial units was presented. Each territorial unit contained one map symbol (Figure 3).

The map symbols contained information about the four attributes of a particular spatial unit, namely food costs (originally blue color, top left position), housing costs (originally red color, top right position), transport costs (originally yellow color, bottom left position) and costs of leisure activities (originally green color, bottom right position), which were indicated by the color and size of the map symbol components (Figure 4). The position and color of the abovementioned attributes were kept constant, only their size was manipulated. 


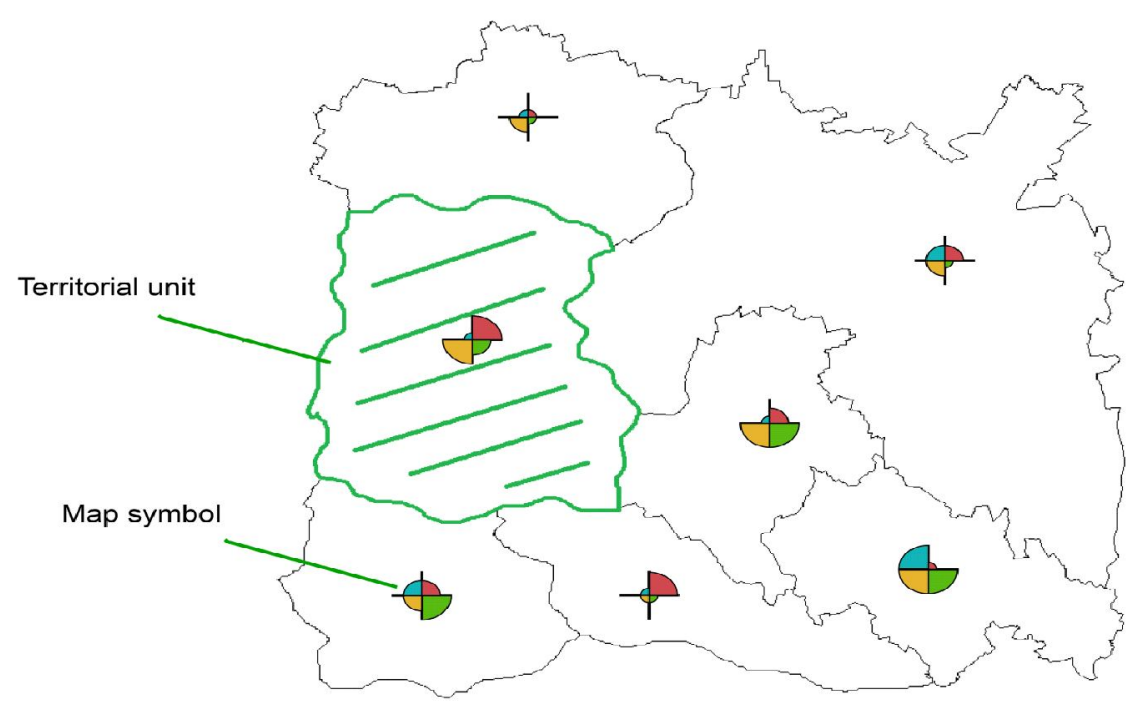

Figure 3 Territorial unit and map symbol in CMMS

(originaly blue colour)

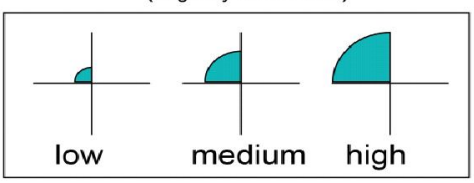

Food costs

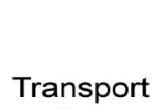

costs

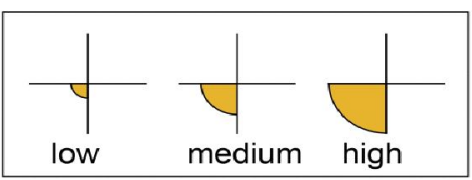

(originaly yellow colour)
MAP SYMBOL

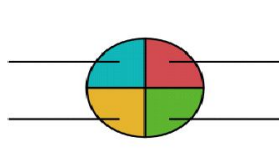

Costs of leisure activities

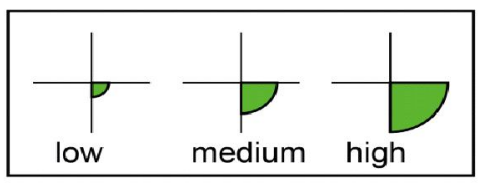

(originaly green colour)

Figure 4 Multivariate map symbol (descriptions were in Czech and traditional/simplified Chinese languages) 
Each map was intentionally created to contain one "holistic" and one "analytic" region comprising several territorial units defined by a specific combination of map symbol characteristics (Figure 6). In the analytic region, one of the map symbol components was kept constant and the rest were random (one-dimensional rule); in the holistic region, all map symbols had globally similar components, but none of them were constant (overall-similarity rule, see Figure 5 ). The remaining map symbol components were completely random to avoid any categorization rule. The analytic and holistic areas were balanced with respect to reading direction.

In group A) the maximum value of the blue parameter (food costs, upper left) was a common attribute in all symbols. In group B), no
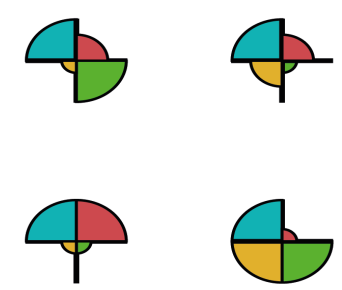

\section{A) One-dimensional rule}

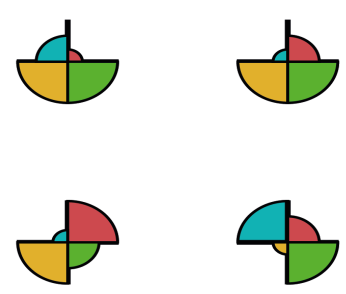

B) Overall-similarity rule

Figure 5 Example of the used analytic A) - left, and holistic B) - right, categorization rules

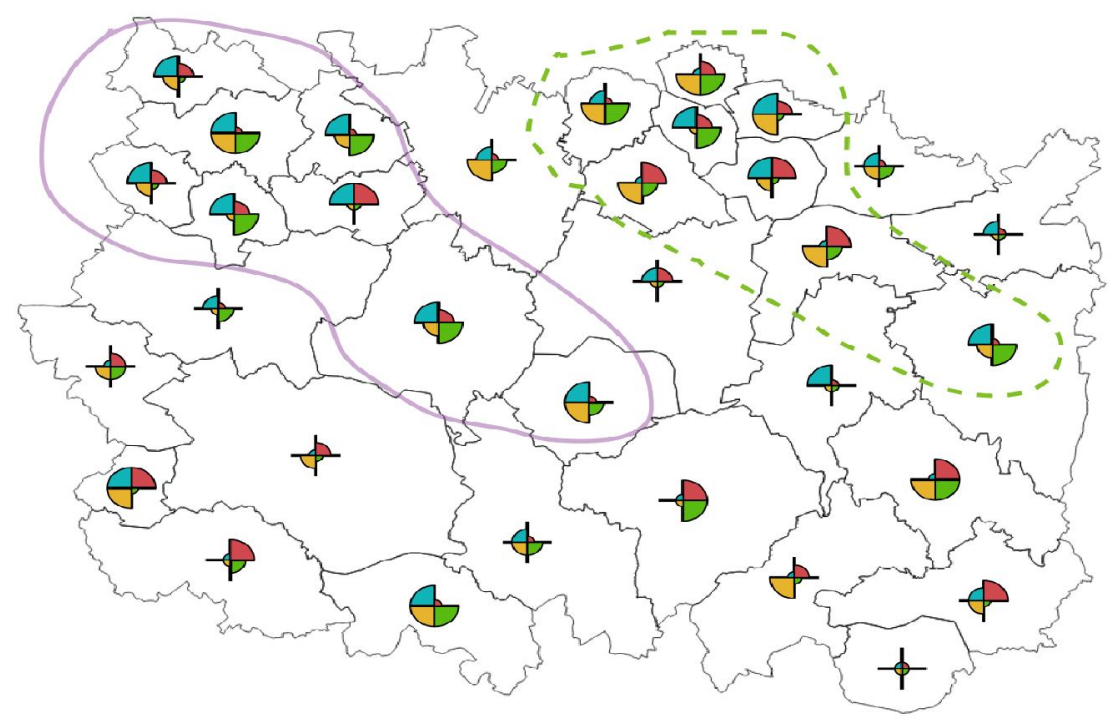

Figure 6 Example of constructed analytic (left solid line) and holistic (right dashed line) map regions 
specific attribute was common to any symbol; they shared overall similarity and equal distribution of values in different parameters $(2 x$ maximum, $1 \mathrm{x}$ medium, and $1 \mathrm{x}$ minimum). Alternative map symbols were created according to principles published by Norenzayan et al. (2002).

Participants were asked to identify and mark a continuous map region comprising at least four territorial units that, according to their judgment, belonged together. The CMMS reported each trial result as a value between 1 and 1 , where a negative value is defined as a holistic categorization and a positive value is defined as an analytic categorization. This value represented the agreement between the predetermined holistic and analytic regions and the real marked areas. A value of \pm 1 represented total agreement, while 0 did not represent any agreement. A control value, calculated as the ratio of marked territorial units within the predetermined areas to the sum of all marked territorial units, was also reported to exclude participants who had incorrectly marked only a negligible number of predetermined areas. A value of .60 and higher was considered a valid response, and therefore $40 \%$ or less marked territorial units beyond predetermined areas. For example, if a trial consists of 10 analytic, 10 holistic and 30 random areas and a participant marks out 11 areas (7 analytic and 4 random), his/her control value is valid (analytic marked areas/all marked areas = $7 / 11=.636$ ) and his/her score is .70 (analytic marked areas/all analytic areas $=7 / 10=.70$ ).

From the research mentioned above, we hypothesized that people with a holistic cognitive style will show a tendency to mark out holistic regions and people with an analytic cognitive style will mark out analytic regions. Analogously, we also assumed that East Asians will mark out the holistic area more often (and the analytic area less often) than Czechs.

\section{Research Sample}

Before data were collected, a power analysis in $G^{*}$ Power (v. 3.1.9.2) was conducted. Setting power at .80 and effect size $f$ at .280 was sufficient to test at least 104 participants (52 from each culture). ${ }^{1}$

We gathered data from 103 participants. Five participants were excluded from further data analysis because of missing data. Out of the remaining 98 participants, 53 participants were Central Europeans (Czech), and 45 participants were East Asians (22 Chinese, 23 Taiwanese). All participants were university students, the majority $(57.1 \%)$ were women and most of them studied psychology $(69.4 \%)$. The age range was $16-55$ years $(M=25.4$, $S D=5.52$ ). From previous studies it seems that several demographic variables are relevant to cognitive style, therefore, we gathered information about cartographic skills and experience (Ooms et al., 2016), SES (Grossmann \& Varnum, 2011), marital status (Bartoš, 2010), size of residence (Jha \& Singh, 2011), number of siblings (based on the number of family members in residence, see Grossmann \& Varnum, 2011) or field of study (Choi, Koo \& Choi, 2007). The detailed descriptive characteristics of the sample are shown in Table 1.

Our research sample was consequently adequate for testing the hypotheses in the first section of results (Cross-Cultural Differences). In the second section (Relationship between Sociocultural, Perception and Cognitive Factors), however, with respect to the sample size, more demanding methods of statistical analysis were used, such as SEM, specifically path analysis. The sample size was relatively inadequate in this case (according to Ding, Velicer, \& Harlow, 1995, the minimum sample size for conducting SEM is about 100-150). The results of SEM therefore needed to be interpreted cautiously. Normality tests were performed for all subscales of the methods used. Non-parametric statistics were used, where the data were not normally distributed.

\footnotetext{
${ }^{1}$ The value of $f$ was selected from previous crosscultural research using the Navon method, in which the effect sizes were $.229-.886(M=.410, S D=$ 216; e.g., Fu, Dienes, Shang, \& Fu, 2013; McKone et al., 2010; Tan, 2016). We selected the middle effect size value $f=.280$.
} 
Table 1 Demographic characteristics of the participants

\begin{tabular}{|c|c|c|c|c|c|}
\hline & & \multirow{2}{*}{$\begin{array}{l}\text { Western } \\
\text { Culture } \\
\text { Czechia }\end{array}$} & \multicolumn{3}{|c|}{ Eastern Culture } \\
\hline & & & China & Taiwan & $\begin{array}{c}\text { East Asia } \\
\text { Total }\end{array}$ \\
\hline \multirow{2}{*}{ Gender } & Male & $25(47.2 \%)$ & $7(31.8 \%)$ & $10(43.5 \%)$ & $17(37.8 \%)$ \\
\hline & Female & $28(52.8 \%)$ & $15(68.2 \%)$ & $13(56.5 \%)$ & $28(62.2 \%)$ \\
\hline \multirow{3}{*}{ Marital status } & Single & $31(58.5 \%)$ & $16(72.7 \%)$ & $13(56.5 \%)$ & $29(64.4 \%)$ \\
\hline & Married & - & $2(9.1 \%)$ & $2(8.7 \%)$ & $4(8.9 \%)$ \\
\hline & In a relationship & $22(41.5 \%)$ & $4(18.2 \%)$ & $8(34.8 \%)$ & $12(26.7 \%)$ \\
\hline \multirow{5}{*}{$\begin{array}{c}\text { Socioeconomic } \\
\text { status }\end{array}$} & Poor & $1(1.9 \%)$ & - & $1(4.3 \%)$ & $1(2.2 \%)$ \\
\hline & Low income & $6(11.3 \%)$ & $4(18.2 \%)$ & $1(4.3 \%)$ & $5(11.1 \%)$ \\
\hline & Middle income & $24(45.3 \%)$ & $6(27.3 \%)$ & $13(56.5 \%)$ & $19(42.2 \%)$ \\
\hline & $\begin{array}{l}\text { Upper-middle } \\
\text { income }\end{array}$ & $19(35.8 \%)$ & $7(31.8 \%)$ & $6(26.1 \%)$ & $13(28.9 \%)$ \\
\hline & High income & $3(5.7 \%)$ & $4(18.2 \%)$ & $2(8.7 \%)$ & $6(13.3 \%)$ \\
\hline \multirow{8}{*}{$\begin{array}{l}\text { Residence } \\
\text { (population) }\end{array}$} & $<1 \mathrm{~K}$ & $6(11.3 \%)$ & $2(9.1 \%)$ & - & $2(4.4 \%)$ \\
\hline & $1-10 K$ & $11(20.8 \%)$ & $1(4.5 \%)$ & $4(17.4 \%)$ & $5(11.1 \%)$ \\
\hline & $10-50 \mathrm{~K}$ & $8(15.1 \%)$ & $1(4.5 \%)$ & $6(26.1 \%)$ & $7(15.6 \%)$ \\
\hline & $50-100 \mathrm{~K}$ & $14(26.4 \%)$ & $2(9.1 \%)$ & $1(4.3 \%)$ & $3(6.7 \%)$ \\
\hline & $100-500 \mathrm{~K}$ & $12(22.6 \%)$ & $4(18.2 \%)$ & $5(21.7 \%)$ & $9(20 \%)$ \\
\hline & $500 \mathrm{~K}-1.5 \mathrm{M}$ & $2(3.8 \%)$ & $4(18.2 \%)$ & $1(4.3 \%)$ & $5(11.1 \%)$ \\
\hline & $1.5 \mathrm{M}-3 \mathrm{M}$ & - & $3(13.6 \%)$ & $4(17.4 \%)$ & $7(15.6 \%)$ \\
\hline & $3 M>$ & - & $4(28.2 \%)$ & $2(8.7 \%)$ & $6(13.3 \%)$ \\
\hline \multirow{2}{*}{ Field of study } & Psychology & $39(73.6 \%)$ & $12(54.5 \%)$ & $17(73.9 \%)$ & $29(64.4 \%)$ \\
\hline & Other & $14(26.4 \%)$ & $10(45.5 \%)$ & $6(16.1 \%)$ & $16(33.6 \%)$ \\
\hline \multirow{5}{*}{$\begin{array}{l}\text { Number of } \\
\text { siblings }\end{array}$} & 0 & $6(11.3 \%)$ & $3(13.6 \%)$ & - & $3(6.7 \%)$ \\
\hline & 1 & $31(58.5 \%)$ & $14(63.6 \%)$ & $12(52.2 \%)$ & $26(57.8 \%)$ \\
\hline & 2 & $11(20.8 \%)$ & $2(9.1 \%)$ & $10(43.5 \%)$ & $12(26.7 \%)$ \\
\hline & 3 & $4(7.5 \%)$ & $1(4.5 \%)$ & - & $1(2.2 \%)$ \\
\hline & 4 or more & $1(1.9 \%)$ & $1(4.5 \%)$ & $1(4.3 \%)$ & $2(4.4 \%)$ \\
\hline $\begin{array}{l}\text { Age range } \\
\text { (mean, SD) }\end{array}$ & & $\begin{array}{l}20-33 \\
(M 23.6 \\
S D 2.32)\end{array}$ & $\begin{array}{c}18-46 \\
(M 27.5 \\
S D 7.43)\end{array}$ & $\begin{array}{c}16-55 \\
(M 27.5 \\
S D 7.24)\end{array}$ & $\begin{array}{c}16-55 \\
(M 27.5 \\
S D 7.25)\end{array}$ \\
\hline
\end{tabular}

\section{Procedure}

Participants were volunteers contacted through university websites and social networks Facebook (Czech and Taiwanese) and WeChat (Chinese). The aforementioned methods were administered in either simplified/traditional Chinese or Czech on PCs using the Hypothesis online testing platform (Popelka, Stachoň,
Šašinka, \& Doležalová, 2016; Šašinka, Morong, \& Stachoň, 2017) in the presence of an instructor. For their participation the participants got a small reward (USB flash disc) or course credits. The sequence of the tests was 1) CFT, 2) CMMS, 3) IISS, 4) sociodemographic questionnaire. The length of the entire procedure was approx. 35-55 minutes. 


\section{Results}

The data were processed with IBM SPSS Statistics (v. 25), IBM SPSS Amos (v. 25) and $R$ (v. 3.4.4, Lavaan and SemTools packages). The results are presented in two sections: CrossCultural Differences and Relationship between Sociocultural, Perceptual and Cognitive Factors. Analysis of the differences between Taiwanese and Chinese participants and also the individual differences between relevant sociocultural variables (e.g., SES, gender, number of siblings, age) were also performed, with no significant differences found in any of the variables. Because of these results, we combined Taiwanese and Chinese participants into a single "Chinese/Taiwanese" group for any subsequent statistical analysis.

\section{Cross-Cultural Differences}

The IISS Questionnaire had a satisfactory reliability in both the independent $\alpha=.895$ (Czech version $\alpha=.815$, Chinese version $\alpha=.929$ ) and interdependent $\alpha=.872$ (Czech version $\alpha=.795$, Chinese version $\alpha=.906$ ) subscales. Furthermore, the subscales did not correlate with each other (Spearman partial $r_{s}=.155$, $p=.177$, culture was a control variable).

The Chinese/Taiwanese were relatively more collectivistic (interdependent subscale) and less individualistic (independent subscale) than the Czechs. The Chinese/Taiwanese scored an average of $5.17(S D=.761)$ in the collectivistic subscale and $5.18(S D=.911)$ in the individualistic subscale, whereas the mean scores of the Czechs were 4.66 ( $S D=$ $.564)$ in the collectivistic subscale and 5.35 $(S D=.502)$ in the individualistic subscale (Figure 7). The statistical significance of these differences was tested with one-way ANOVA. The differences were significant only in the case of collectivism: $F(1,96)=14.456, p<.001$, with medium effect size $\left(\eta^{2}=.131\right)$. No significant differences were found between the groups in the individualism subscale (Mann-Whitney $U=1105.5, p=.535, r=.063)$. The data were also analyzed with respect to sociodemographic variables. No other significant relationships were observed (for the complete list of collected variables, see Table 1 ).

A medium correlation was found between both local and global CFT tasks (Spearman partial $r_{s}=.564, p<.001$, culture was a control variable). Two participants were removed from

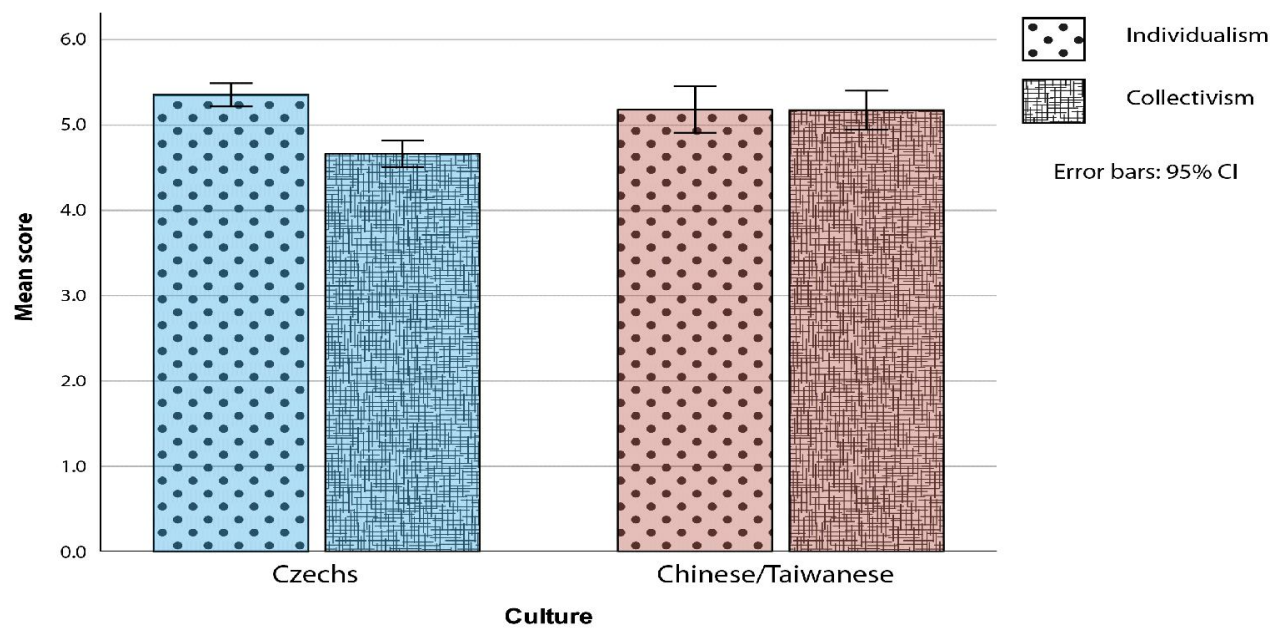

Figure 7 IISS - mean scores 
further analysis because of their high error rates (more than four errors in each task).

The results suggest that all participants had significantly quicker reaction times in the global task than in the local task (Wilcoxon signed-rank test $Z=-6.634, p<.001, r=-.677$ ). The findings also show that Czechs were quicker than Chinese/Taiwanese in both local and global tasks. The average reaction time of the Czech participants in the global task was 0.99 sec. $(S D=.209)$ compared to the Chinese/Taiwanese participants with an average reaction time of $1.66 \mathrm{sec}$. $(S D=.466)$. A similar pattern was observed in the local task, where the average reaction time of the trial solution was $1.13 \mathrm{sec}$. $(S D=.144)$ for the Czechs and $1.77 \mathrm{~s}(S D=.387)$ for the Chinese/Taiwanese participants (Figure 8). Czechs were significantly quicker in both the global $(U=204, p<$ $.001, r=-.711)$ and local $(F(1,95)=121.960, p$ $\left.<.001, \eta^{2}=.562\right)$ tasks, with large effect sizes.

These differences in reaction times, however, cannot be interpreted in the $\mathrm{A} / \mathrm{H}$ paradigm as any difference in cognitive style but rather as differences in the emphasis that both groups placed on the speed of the CFT solution (Kukaňová, 2017; Yates et al., 2010). We also calculated the global precedence score using the aforementioned procedure of difference, specifically by subtracting the local reaction times from global reaction times. Although the Czech participants had a relatively higher global precedence score $(M=.139$, $S D=.210)$ than the Chinese/Taiwanese participants $(M=.108, S D=.574)$, this difference was not significant $(U=949, p=.083, r=$ -.175) (Figure 9).

The final method applied was CMMS. Four participants were removed from further analysis because of their high error rate (participants that marked less than three territorial units into one continuous map region). The results on a scale between -1 (holistic) to 1 (analytic) show that Czechs categorized in maps more analytically $(M=.044, S D=.360)$ and East Asians categorized in maps more holistically $(M=-.063, S D=.172)$ (Figure 10). This cultural difference was statistically significant $(U=795, p=.021)$, with a small effect size $(r=-.235)$. However, the results show that both groups used a similar cognitive style to categorize map symbols and only small differences in cognitive strategies were found. Moreover, both groups scored relatively close to zero, which is probably caused by using various categorization strategies across different trials,

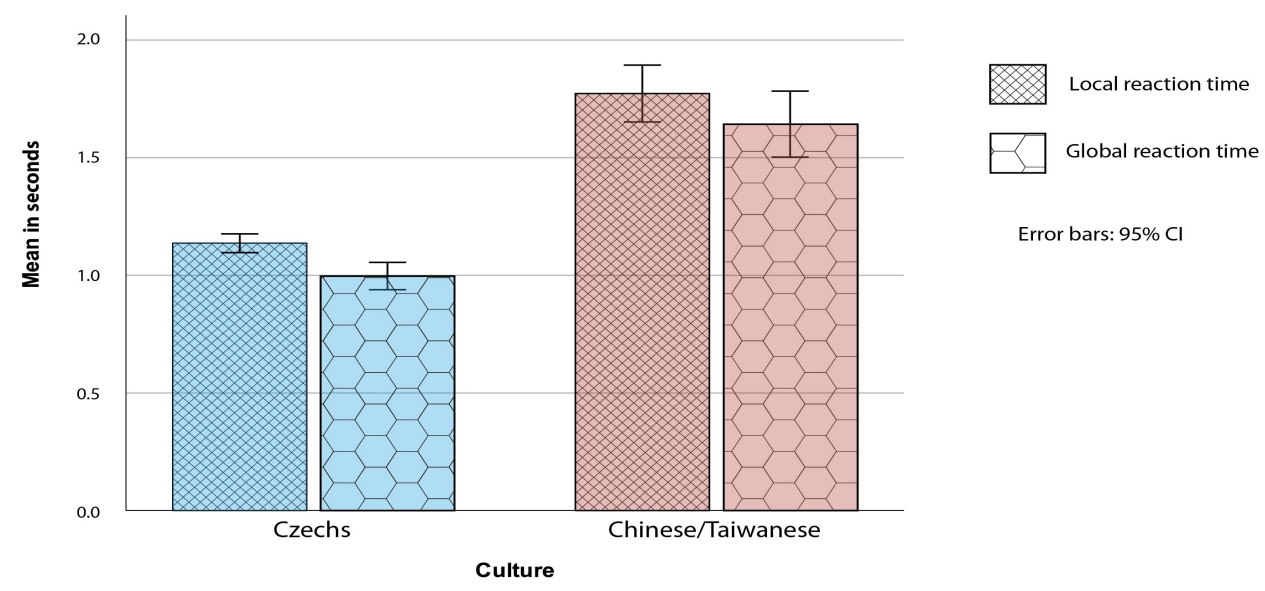

Figure 8 CFT - mean reaction times 


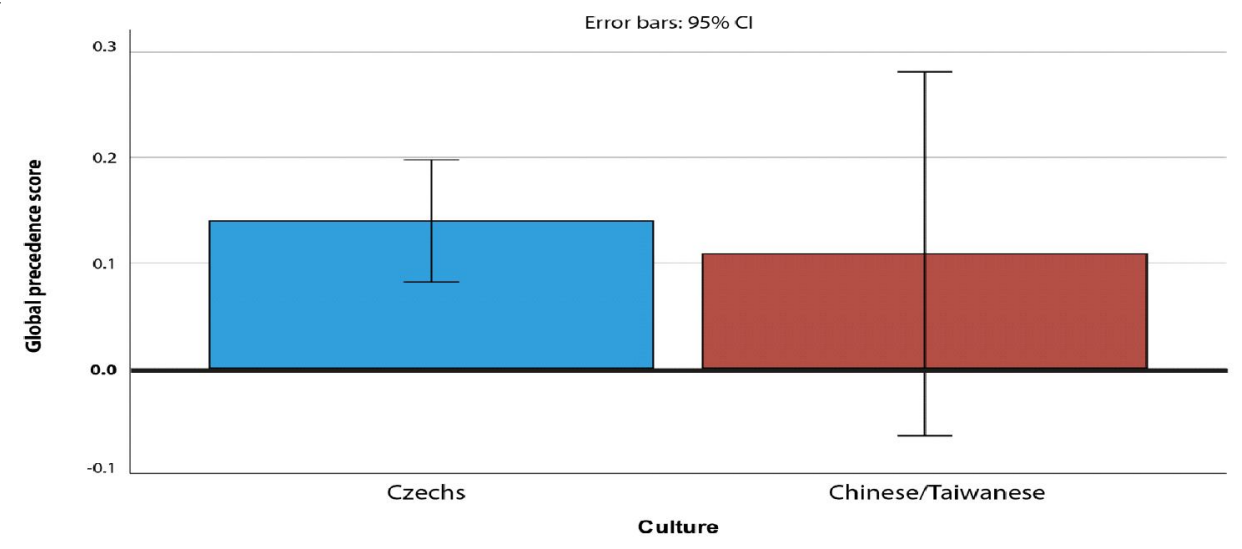

Figure 9 CFT - Mean global precedence scores (higher values mean higher global precedence)

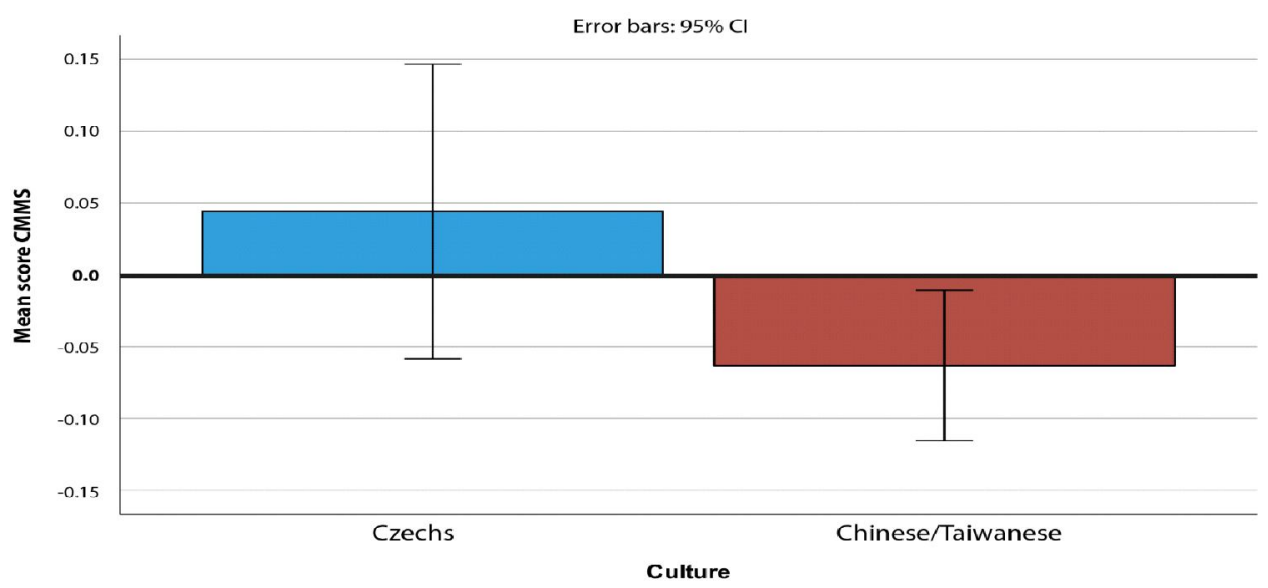

Figure 10 CMMS - Cross-cultural differences in map categorization (High value = analytic, low value $=$ holistic $)$.

because absolute scores were higher for both Czechs $(M=.461, S D=.183)$ and Asians $(M=$ $.247, S D=.148)$.

\section{Relationship between Sociocultural, Percep- tual and Cognitive Factors}

We performed a Spearman partial correlation and a path analysis (type of SEM) to verify the research model at individual level in order to obtain an improved and deeper understanding of the phenomena under scrutiny and their mutual relationships.

Using a non-parametric Spearman partial correlation with culture as control variable, only weak correlations were found between the CMMS scores and the CFT global reaction times $\left(r_{s}=.222, p=.035\right)$ and between the 
CMMS scores and the CFT global precedence scores $\left(r_{s}=-.216, p=.040\right)$. The whole correlation matrix is shown in Table 2:

A path analysis was also performed using the expectation-maximization (EM) method to estimate missing values and an asymptotically distribution-free (ADF) method, which is adequate for non-parametric data. Since both cultures were analyzed together, culture was used as a "control variable". Two models were analyzed: Model 1 comprised CFT reaction times, and Model 2 was computed with the calculated CFT global precedence score (Figure 11). Both models showed a very good fit (Table 3).

Path analysis for Model 1 revealed a weak direct effect of individualism (IISS independent self-construal scale) on CFT local reaction times $(\beta=-.250, B=-.167, p=.003)$ and a weak direct effect of collectivism (IISS interdependent self-construal scale) on CFT global reaction times $(\beta=-.196, B=-.135, p=.047)$. The higher score in individualism therefore indicated a quicker reaction time in the local

Table 2 Spearman partial correlation matrix

\begin{tabular}{lcccccc}
\hline & 1. & 2. & 3. & 4. & 5. & 6. \\
\hline 1. Individualism & - & & & & & \\
2. Collectivism & .155 & - & & & \\
3. CFT local RT & .002 & .073 & - & & \\
4. CFT global RT & -.026 & -.140 & $.564^{* *}$ & - & \\
5. Global precedence score & .125 & .183 & .176 & $-.546^{* *}$ & - & \\
6. CMMS & .066 & .147 & -.063 & $.222^{*}$ & $-.216^{*}$ & - \\
\hline Note ${ }^{*} \mathrm{p}<.05^{* *} \mathrm{p}<.001$ & & & & & &
\end{tabular}

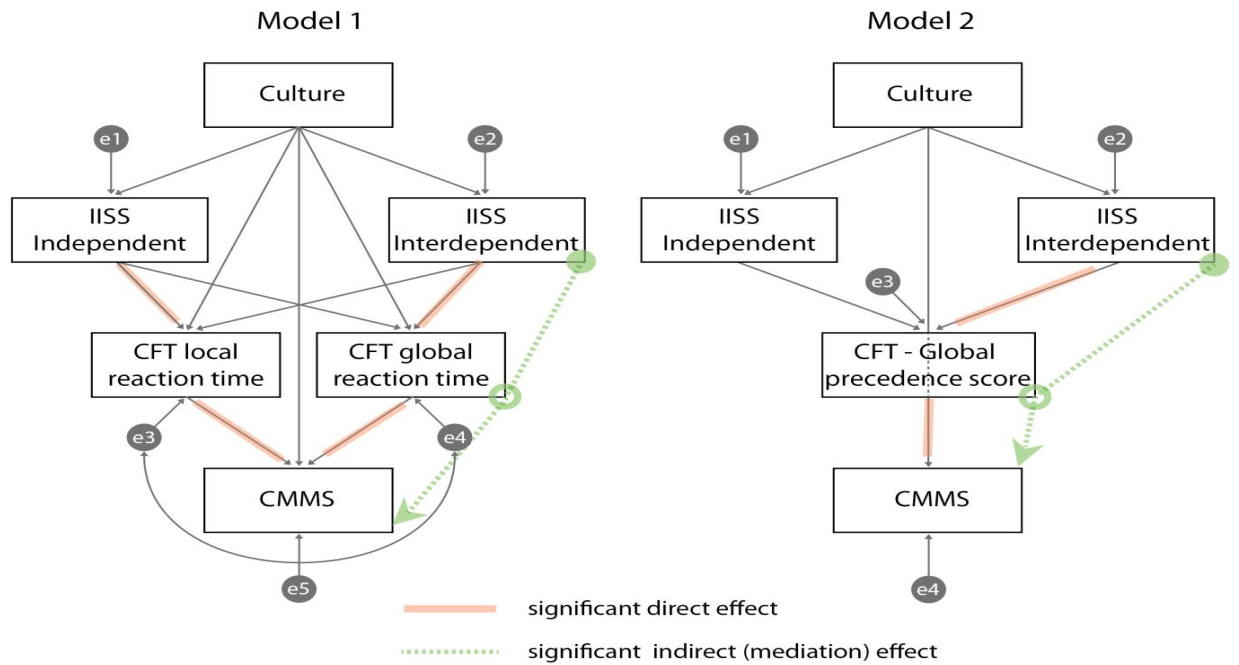

Figure 11 Path analysis models - Model 1 (left), Model 2 (right) 
Table 3 Models fits

\begin{tabular}{lccccccc}
\hline Model & Chi-square & p-value & CFI & RMSEA & AIC & BIC & ECVI \\
\hline Model 1 & $\mathrm{X}^{2}(3)=3.897$ & .273 & .995 & .057 & 39.897 & 85.289 & .438 \\
\hline Model 2 & $\mathrm{X}^{2}(3)=4.435$ & .218 & .960 & .073 & 28.435 & 58.697 & .312 \\
\hline
\end{tabular}

task, and the higher score in collectivism indicated a quicker reaction time in the global task, i.e., I/C scores weakly predicted the performance in CFT tasks. Moderate direct effects of the CFT global reaction times $(\beta=.713, B=$ $.450, p<.001)$ and the CFT local reaction times $(\beta=-.776, B=-.521, p<.001)$ on the CMMS scores were also found. These results suggest that the analytic perceivers (persons with a quicker CFT local reaction time) tended to use an analytic manner of categorizing point multivariate map symbols, and that the holistic perceivers (persons with quicker CFT global reaction time) used a rather holistic manner of categorizing point multivariate map symbols. In other words, the CFT reaction times satisfactorily predicted the map categorization style. In order to estimate the indirect effects of I/C on point multivariate map symbol categorization, bootstrapping $(N=2000, \mathrm{Cl}=95 \%)$ was performed, and a very weak indirect (mediation) effect of collectivism (IISS interdependent self-construal scale) on the CMMS score $(\beta=$ $-.175, B=-.077, p=.028$ ) was detected.

Path analysis performed on Model 2 showed a weak direct effect of collectivism (IISS interdependent self-construal scale) on the CFT global precedence score $(\beta=.357, B=.156$, $p=.017)$. This finding suggests that collectivistic people tended to use a more global distribution of attention that is characteristic of the holistic cognitive style. A moderate direct effect of the CFT global precedence score on map categorization $(\beta=-.502, B=-.502, p<.001)$ was also observed, i.e., participants who showed a relatively more global distribution of attention, categorized symbols in maps according to relatively more holistic rules, and vice versa, participants who showed a relatively more local distribution of attention, were prone to use relatively more analytic rules of categorization. A very weak significant indirect (mediation) effect of collectivism (ISS interdependent self-construal scale) on map categorization $(\beta=-.179, B=-.078, p=.026)$ was also found after bootstrapping $(N=2000, \mathrm{Cl}=95 \%)$.

It should be noted that we reported only significant relationships. However, as shown in Figure 11, we included all plotted relations in the models (i.e., IIISS independent on CFT global RT and IISS interdependent on CFT local RT in Model 1 and IISS independent on CFT global precedence score in Model 2). Moreover, we also performed indirect (meditation) effect of individualism (IISS independent selfconstrual scale) on map categorization with no significant results in both models. The exogenous control variable "culture" had statistically significant and large regression coefficients on all endogenous variables in the models. Nevertheless, we did not report these results because we added it to our models only in order to weaken the influence of other variables. Moreover, the apparent dissension between insignificant correlation coefficients and significant regression coefficients of path analysis could be explained by suppression effect and Simpson's paradox (see MacKinnon, Krull, \& Lockwood, 2000; Tu, Gunnell, \& Gilthorpe, 2008), which postulates that a more complex statistical model can reduce, reverse or even enhance the relationships between variables.

\section{Discussion}

The aims of the presented study were: 1) to compare $\mathrm{I} / \mathrm{C}$ and $\mathrm{A} / \mathrm{H}$ cognitive styles and map categorization in Czech and East Asian (Chinese/Taiwanese) university students, and 2) 
to investigate and verify the theoretical model of relationships between $\mathrm{I} / \mathrm{C}$ and $\mathrm{A} / \mathrm{H}$ cognitive styles and between $\mathrm{A} / \mathrm{H}$ cognitive styles and their behavioral manifestation in the process of map categorization.

The results suggest that the Czech participants showed a significantly lower level of collectivism (interdependent self-construal scale) than did the Chinese/Taiwanese participants and a similar level of individualism (independent self-construal scale). Our results partly support the current theory that describes the West as relatively less collectivistic than the East (Hofstede, 1983; Markus \& Kitayama, 1991; Nisbett et al., 2001; Triandis \& Gelfand, 1998). Furthermore, a similar level of individualism corresponds to the empirical research in $\mathrm{I} / \mathrm{C}$ in post-communist countries (Kolman et al., 2003; Varnum et al., 2008) and even with previous research in I/C in Czechia (Bartoš, 2010; Čeněk 2015). This finding also supports the claims of rapid individualization in the young East Asian populations (e.g., Moore, 2005; Steele \& Lynch, 2013).

The results of the CFT show that all of the participants performed the global tasks more quickly than the local tasks, which is consistent with previous findings (Navon, 1977). However, our participants were generally slower compared to the original study (Navon, 1977). This fact was most probably caused by the way of responding (mouse click instead of keyboard buttons) because mouse response process has in contrast with keyboard response process one extra step (i.e., moving the mouse cursor above the response option). Our results also indicate cross-cultural differences in the general reaction times of CFT stimuli processing. The Czech participants were significantly quicker in both the global and local tasks. However, as mentioned above, these differences in reaction times demonstrated rather differences in the emphasis that both groups placed on the speed than differences in cognitive style (Kukaňová, 2017; Yates et al., 2010). The comparison of the global precedence scores (calculated from CFT global and local reaction times) showed no differences in global/local processing between the Czechs and Chinese/Taiwanese, which was contrary to our expectations. The results of the CFT could be seen as a contradiction to the notion of the "analytic West" and "holistic East" (Nisbett et al., 2001; Nisbett \& Masuda, 2003; Nisbett \& Miyamoto, 2005). However, it is still not clear whether Central Europeans count as the "analytic West". For example, Varnum et al. (2008) showed that Central European post-communist countries are relatively more holistic in their patterns of attention than Western Europe. Other empirical research, comparing the sensitivity to the context of Czech vs. Czech Vietnamese (Čeněk, 2015), and Czech vs. Chinese (Stachoň et al., 2018, Stachoň et al., 2019), reported mixed or contradictory results in terms of the expected differences in cognitive style.

The results of the CMMS show that the Czech participants categorized more analytically in maps, whereas the Chinese/Taiwanese categorized more holistically. This result agrees with the theory that Westerners use slightly more analytic categorization patterns and Easterners use more holistic categorization (Chiu, 1972; Ji et al., 2004; Norenzayan et al., 2002). However, the effect size of this significant difference was relatively small.

Path analysis was used to test the validity of two structural models of relationships between the variables of interest. Both evaluated models (CFT local and global reaction times and the global precedence score) showed a satisfactory good fit. The results of the path analysis show that $\mathrm{I} / \mathrm{C}$ is a weak predictor of the level of global/local distribution of attention, i.e., collectivist persons tended to use a holistic cognitive style, and individualistic persons tended to use a rather analytic cognitive style. These findings partly support the theory of holistic and analytic cognitive styles (Nisbett, 2003; Nisbett et al., 2001; Triandis \& Gelfand, 1998), although the values of the path coefficients were relatively small. The path analysis also did not find all of the expected direct and indirect effects of $\mathrm{I} / \mathrm{C}$ on the scores of the CFT and the CMMS. The aforementioned findings were, therefore not a conclusive argument to support the $\mathrm{A} / \mathrm{H}$ cognitive style theory in cross- 
cultural context (cf. Nisbet et al., 2001). As with several other studies that did not find any relationship between $\mathrm{I} / \mathrm{C}$ and $\mathrm{A} / \mathrm{H}$ cognitive style (e.g., Davidoff et al., 2008; McKone et al., 2010; Takano \& Osaka, 1999), it may be possible that this relationship could be different from what researchers expect, or perhaps even nonexistent. Our findings of unconvincing yet significant relationships could also be explained in theoretical arguments, which maintain that the $\mathrm{I} / \mathrm{C}$ and $\mathrm{A} / \mathrm{H}$ cognitive styles only manifest at a cultural (i.e., cross-cultural comparison) not individual level (i.e., SEM and path analysis; cf. Na et al., 2010). Nevertheless, we would like to emphasize that the sample size was, in this case, relatively inadequate for SEM, therefore its results should be understood as only exploratory.

The concept of I/C and its measurement with self-report scales have recently been subject to disagreement from many scholars. This criticism mainly cites the lack of concurrent, discriminant and construct validity, insufficient conceptualization, a reductionist and dichotomous approach and insufficient psychometric characteristics in questionnaires (for review, see Levine et al., 2003; Matsumoto, 1999; Oyserman et al., 2002; Vignoles et al., 2016). For example, if the individual level of $\mathrm{I} / \mathrm{C}$ can be significantly influenced by priming, then it means that $\mathrm{I} / \mathrm{C}$ is not as stable in time as it is generally assumed (Gardner, Gabriel, \& Lee, 1999; Oyserman \& Lee, 2008). Moreover, according to the results of meta-analytical studies and systematic reviews, the West should not be described as strictly individualistic nor the East as purely collectivistic (Levine et al., 2003; Oyserman et al., 2002; Takano \& Osaka, 1999; Takano \& Osaka, 2018). Most recently, for example, Hakim et al. (2017) compared the levels of individualism and collectivism of American and Asian international students and found, contrary to expectations, that Americans were significantly more collectivistic, whereas the Asian students were significantly more individualistic.

Path analysis also found that global/local distribution of attention had a moderate predictive power on categorization in both of the tested models, i.e., analytic perceivers (defined by the CFT global precedence score) used analytic categorization in maps, whereas holistic perceivers used holistic categorization. This finding is consistent with the research theory (Chiu, 1972; Ji et al., 2004; Norenzayan et al., 2002) and the empirical research (Kubíček et al., 2016; Šašinka et al., 2018; Stachoň et al., 2019). Consequently, the cognitive style that is characterized as a perceptual process is presumably manifested in higher cognitive processes, such as map reading and categorization.

\section{Conclusions}

The article describes cross-cultural differences in western and eastern cultures, between Czech and Chinese/Taiwanese university students, respectively. The theoretical background of the research was based on the theory of analytic and holistic cognitive styles and the dimensions of individualism and collectivism. Two main objectives were defined: first, to identify the possible cross-cultural differences and similarities between Czechs and Chinese/Taiwanese, and second, to verify the entire research model and the relationships between $\mathrm{A} / \mathrm{H}$ cognitive style and $\mathrm{I} / \mathrm{C}$ at individual levels. For this purpose, we also developed a new method (CMMS) in order to study how $A / H$ cognitive style was manifested during categorization in map reading. The results suggest that cross-cultural differences exist between both cultures, especially at the level of collectivism (Czechs were less collectivist than the Chinese/Taiwanese) and categorization in map reading (Czechs used more analytic and less holistic categorization). Neither individual differences (e.g., SES, gender, age) nor differences in cognitive style measured by the CFT between Czech and East Asians were found. The findings also indicate that $\mathrm{I} / \mathrm{C}$ is a weak predictor of $\mathrm{A} / \mathrm{H}$ cognitive style and that $\mathrm{A} / \mathrm{H}$ cognitive style moderately predicts categorization in map reading.

These results contradict the East-West dichotomy and suggest that the culture of Central Europe (specifically Czechia) is much more 
similar to the East than expected from the literature. However, more cross-cultural research of typically Western, typically Eastern and Central European cultures is needed for an improved understanding of the real influence of culture on human perception and cognition in regions outside the East-West dichotomy. Based on the presented results, future research should focus on verification of Nisbett's (2001) vs. Kozhevnikov's (2014) models of cognitive styles. Above all, specify the number of cognitive style families, investigate the stability/flexibility of cognitive styles, and inspect the developmental aspects (e.g., children of different age) of cognitive style and its adaptive nature (e.g., research on expatriates during the process of cultural adaptation) is also suggested.

\section{Acknowledgement}

This publication was supported by the Czech Science Foundation (GC19-09265J: The influence of socio-cultural factors and writing system on perception and cognition of complex visual stimuli).

\section{References}

Angsüsser, S. (2014). Possible reasons for size differences between point symbols in German and Chinese city maps. In T. Bandrova \& M. Konecny (Eds.), Proceedings of the 5th International Conference on Cartography \& GIS (pp. 268-277), Sofia: Bulgarian Cartographic Association. https:/ /cartography495gis.com/docsbca/5ICCandGIS Proceedings.pdf

Bartoš, F. (2010). Individualismus a kolektivismus v české populaci a jejich souvislost $\mathrm{s}$ narcismem. Sociólogia, 42(2), 134-160.

Čeněk, J. (2015). Cultural dimension of individualism and collectivism and its perceptual and cognitive correlates in cross-cultural research. The Journal of Education, Culture and Society, 6(2), 210 225. https://doi.org/10.15503/jecs20152.210.225

Chiu, L. H. (1972). A Cross-cultural comparison of cognitive styles in Chinese and American children. International Journal of Psychology, 7(4), 235242. https://doi.org/10.1080/00207597208246604

Choi, I., Koo, M., \& Choi, J. (2007). Individual differences in analytic versus holistic thinking. Personal- ity and Social Psychology Bulletin, 33(5), 691705. https://doi.org/10.1177/0146167206298568

Choi, I., \& Nisbett, R. (1998). Situational salience and cultural differences in the correspondence bias and actor-observer bias. Personality and Social Psychology Bulletin, 24(9), 949-960. https:// doi.org/10.1177/0146167298249003

Choi, I., Nisbett, R., \& Norenzayan, A. (1999). Causal attribution across cultures: Variation and universality. Psychological Bulletin, 125(1), 47-63. https://doi.org/10.1037/0033-2909.125.1.47

Chua, H., Boland, J., \& Nisbett, R. (2005). Cultural variation in eye movements during scene perception. Proceedings of the National Academy of Sciences of the United States of America, 102(35), 12629-12633. https://doi.org/10.1073/pnas. 0506162102

Cieślikowska, D. (2006). Object and context in perception and memory: Polish-Chinese research on analytic and holistic cognitive styles. Studia Psychologiczne (Psychological Studies), 44(1), 80-99.

Cohen, N., \& Ariely, T. (2011). Field research in conflict environments: Methodological challenges and snowball sampling. Journal of Peace Research, 48(4), 423-435. https://doi.org/10.1177/ 0022343311405698

Davidoff, J., Fonteneau, E, \& Fagot, J. (2008). Local and global processing: Observations from a remote culture. Cognition, 108(3), 702-709. https:// doi.org/10.1016/j.cognition.2008.06.004

Ding, L., Velicer, W., \& Harlow, L. (1995). Effect of estimation methods, number of indicators per factor and improper solutions on structural equation modeling fit indices. Structural Equation Modeling, 2(2), 119-143. https://doi.org/10.1080/ 10705519509540000

Federici, S., Stella, A., Dennis, J., \& Hündsfelt, T. (2011). West vs. West like East vs. West? A comparison between Italian and US American context sensitivity and fear of isolation. Cognitive Processing, 12(2), 203-208. https://doi.org/10.1007/ s10339-010-0374-8

Fu, Q., Dienes, Z., Shang, J., \& Fu, X. (2013). Who learns more? Cultural differences in implicit sequence learning. PLOS ONE, 8(8), e71625. https:/ /doi.org/10.1371/journal.pone.0071625

Gardner, W., Gabriel, S., \& Lee, A. (1999). "I" value freedom, but "we" value relationships: Selfconstrual priming mirrors cultural differences in judgment. Psychological Science, 10(4), 321-326. https://doi.org/10.1111/1467-9280.00162

Gerlach, Ch., \& Poirel, N. (2018). Navon's classical paradigm concerning local and global processing relates systematically to visual object classifica- 
tion performance. Scientific Reports, 8(1), 324 https://doi.org/10.1038/s41598-017-18664-5

Graff, M. (2003). Learning from web-based instructional systems and cognitive style. British Journal of Educational Technology, 34(4), 407-418. https:/ /doi.org/10.1111/1467-8535.00338

Grossmann, I., \& Varnum, M. (2011). Social class, culture, and cognition. Social Psychological and Personality Science, 2(1), 81-89. https://doi.org/ $10.1177 / 1948550610377119$

Hakim, N., Simons, D., Zhao, H., \& Wan, X. (2017) Do Easterners and Westerners differ in visual cognition? A preregistered examination of three visual cognition tasks. Social Psychological and Personality Science, 8(2), 1-11. https://doi.org/ 10.1177/1948550616667613

Herman, L., Juřík, V., Stachoň, Z., Vrbík, D., Russnák, J., \& Rezník, T. (2018). Evaluation of user performance in interactive and static 3D maps. ISPRS International Journal of Geo-Information, 7(11), 1-25. https://doi.org/10.3390/ijgi7110415

Hermans, H., \& Kempen, H. (1998). Moving cultures: The perilous problems of cultural dichotomies in a globalizing world. American Psychologist, 53(10), 1111-1120. https://doi.org/10.1037/0003-066X.53. 10.1111

Hofstede, G. (1983). The cultural relativity of organizational practices and theories. Journal of International Business Studies, 14(2), 75-89. https:// doi.org/10.1057/palgrave.jibs.8490867

Jha, S. D., \& Singh, K. (2011). An analysis of individualism-collectivism across Northern India. Journal of the Indian Academy of Applied Psychology, 37(1), 149-156.

Ji, L., Peng, K., \& Nisbett, R. (2000). Culture, control, and perception of relationships in the environment. Journal of Personality and Social Psychology. 78(5), 943-955. https://doi.org/10.1037//00223514.78 .5 .943

Ji, L., Zhang, Z., \& Nisbett, R. (2004). Is it culture or is it language? Examination of language effects in cross-cultural research on categorization. Journal of Personality and Social Psychology, 87(2), 57-65. https://doi.org/10.1037/0022-3514.87.1.57

Kitayama, S., Duffy, S., Kawamura, T., \& Larsen, J. T. (2003). Perceiving an object and its context in different cultures: A cultural look at new look. Psychological Science, 14(3), 201-206. https:// doi.org/10.1111/1467-9280.02432

Kitayama, S., Ishii, K., Imada, T., Takemura, K., \& Ramaswamy, J. (2006). Voluntary settlement and the spirit of independence: Evidence from Japan's "Northern frontier." Journal of Personality and Social Psychology, 91(3), 369-384. https://doi.org/ 10.1037/0022-3514.91.3.369
Kitayama, S., Park, H., Sevincer, A., Karasawa, M. \& Uskul, A. (2009). A cultural task analysis of implicit independence: Comparing North America, Western Europe, and East Asia. Journal of Personality and Social Psychology, 97(2), 236-255. https://doi.org/10.1037/a0015999

Knight, K., \& Nisbett, R. (2007). Culture, class, and cognition: Evidence from Italy. Journal of Cognition and Culture, 7(3), 283-291. https://doi.org/ $10.1163 / 156853707 \times 208512$

Kolman, L., Noorderhaven, N., Hofstede, G., Dienes, E. (2003). Crosscultural differences in Central Europe. Journal of Managerial Psychology, 18(1), 76-88. https://doi.org/10.1108/ 02683940310459600

Köster, M., Castel, J., Gruber, T., \& Kärtner, J. (2017). Visual cortical networks align with behavioral measures of context-sensitivity in early childhood. Neurolmage, 163(2017), 413-418. https://doi.org/ 10.1016/j.neuroimage.2017.08.008

Kozhevnikov, M., Evans, C., \& Kosslyn, S. M. (2014). Cognitive style as environmentally sensitive individual differences in cognition: A modern synthesis and applications in education, business, and management. Psychological Science in the Public Interest, 15(1), 3-33. https://doi.org/10.1177/ 1529100614525555

Kubíček, P., Šašinka, Č., Stachoň, Z., Štěrba, Z., Apeltauer, J., \& Urbánek, T. (2016). Cartographic design and usability of visual variables for linear features. The Cartographic Journal, 54(1), 91102. https://doi.org/10.1080/00087041.2016. 1168141

Kukaňová, M. (2017). Porovnání dvou typů vizualizací z hlediska percepční a kognitivní zátěže a kognitivních schopností jedince. [Comparison of the two types of visualization in terms of perceptual and cognitive load, and personal cognitive abilities]. [Doctoral Dissertation]. Brno: Masaryk University. https://is.muni.cz/auth/th/ djk10/

Levine, T., Bresnahan, M., Park, H., Lapinski, M., Wittenbaum, G., Shearman, S., ... \& Ohashi, R. (2003). Self-construal scales lack validity. Human Communication Research, 29(2), 210-252. https:/ /doi.org/10.1111/j.1468-2958.2003.tb00837.x

Lewandowsky, S., Herrmann, D. J., Behrens, J. T., Li, S., Pickle, L., \& Jobe, J. B. (1993). Perception of clusters in statistical maps. Applied Cognitive Psychology, 7(6), 533-551. https://doi.org/10.1002/ acp.2350070606

Lu, L., \& Gilmour, R. (2007). Developing a new measure of independent and interdependent views of the self. Journal of Research in Personality, 41(1), 249-257. https://doi.org/10.1016/j.jrp.2006.09.005 
MacEachren, A. (1995). How maps work: Representation, visualization, and design. New York: Guilford Press.

MacKinnon, D. P., Krull, J. L., \& Lockwood, C. M (2000). Equivalence of the mediation, confounding and suppression effect. Prevention Science: The Official Journal of the Society for Prevention Research, 1(4), 173-181. https://doi.org/10.1023/ A:1026595011371

Markus, H., \& Kitayama, S. (1991). Culture and the self: Implications for cognition, emotion, and motivation. Psychological Review, 98(2), 224-253. https://doi.org/10.1037/0033-295X.98.2.224

Masuda, T. (2017). Culture and attention: Recent empirical findings and new directions in cultural psychology. Social and Personality Psychology Compass, 11(12), e12363. https://doi.org/10.1111/ spc3.12363

Masuda, T., \& Kitayama, S. (2004). Perceived-induced constraint and attitude attribution in Japan and in the US: A case for cultural dependence of the correspondence bias. Journal of Experimental Social Psychology, 40(3), 409-416. https:// doi.org/10.1016/j.jesp.2003.08.004

Masuda, T., \& Nisbett, R. (2001). Attending holistically versus analytically: Comparing the context sensitivity of Japanese and Americans. Journal of Personality and Social Psychology, 81(5), 922934. https://doi.org/10.1037//0022-3514.81.5. 922

Masuda, T., \& Nisbett, R. (2006). Culture and change blindness. Cognitive Science, 30(2), 381-399. http://dx.doi.org/10.1207/s15516709cog000063

Matsumoto, D. (1999). Culture and self: An empirical assessment of Markus and Kitayama's theory of independent and interdependent self-construals. Asian Journal of Social Psychology, 2(3), 289 310. https://doi.org/10.1111/1467-839X.00042

McCleary, G. (1975). In pursuit of the map user. In J. Kavaliunas (Ed.), Proceedings of the International Symposium on Computer-Assisted Cartography: Auto Carto II (pp. 238-250), Washington: U.S. Department of Commerce, Bureau of the Census. http://cartogis.org/docs/proceedings/archive/autocarto-2/pdf/auto-carto-2.pdf

McKone, E., Davies, A., Fernando, F., Aalders, R. Leung, H., Wickramariyaratne, T., \& Platow, M. (2010). Asia has the global advantage: Race and visual attention. Vision Research, 50(16), 15401549. https://doi.org/10.1016/j.visres.2010.05.010

Miyamoto, Y., \& Kitayama, S. (2002). Cultural variation in correspondence bias: The critical role of attitude diagnosticity of socially constrained behavior. Journal of Personality and Social Psychol- ogy, 83(5), 1239-1248. https://doi.org/10.1037/ 0022-3514.83.5.1239

Montello, D. R., (2002). Cognitive map-design research in the twentieth century: Theoretical and empirical approaches. Cartography and Geographic Information Science, 29(3), 283-304. https://doi.org/10.1559/152304002782008503

Morita, T. (2004). Ubiquitous mapping in Tokyo. International joint workshop on ubiquitous, pervasive and Internet mapping (UPIMap2004), Tokyo, Japan. https://www.geospatialweb.com/www. ubimap.net/upimap2004/html/papers/UPIMap04-A01-Morita.pdf

Moore, R. (2005). Generation Ku: Individualism and China's millennial youth. Ethnology, 44(4), 357376. http://doi.org/10.2307/3774095

Morris, M., \& Peng, K. (1994). Culture and cause: American and Chinese attributions for social and physical events. Journal of Personality and Social Psychology, 67(6), 949-971. https://doi.org/ 10.1037/0022-3514.67.6.949

Na, J., Grossmann, I., Varnum, M., Kitayama, S., Gonzalez, R., \& Nisbett, R. (2010). Cultural differences are not always reducible to individual differences. Proceedings of the National Academy of Sciences of the United States of America, 107(14), 6192-6197. https://doi.org/10.1073/ pnas.1001911107

Navon, D. (1977). Forest before trees: The precedence of global features in visual perception. Cognitive Psychology, 9(3), 353-383. https://doi.org/ 10.1016/0010-0285(77)90012-3

Nelson, E., Dow, D., Lukinbeal, C., \& Farley, R. (1997). Visual search processes and the multivariate point symbol. Cartographica, 34(4), 19-33. http://doi.org/ 10.3138/15T3-3222-X25H-35JU

Nisbett, R. (2003). The Geography of thought: How Asians and Westerners think differently... and why. New York: The Free Press.

Nisbett, R., \& Masuda, T. (2003). Culture and point of view. Proceedings of the National Academy of Sciences, 100(19), 11163-11170. https://doi.org/ 10.1073/pnas. 1934527100

Nisbett, R., \& Miyamoto, Y. (2005). The Influence of culture: Holistic versus analytic perception. Trends in Cognitive Sciences, 9(10), 467-473. https:// doi.org/10.1016/j.tics.2005.08.004

Nisbett, R., Peng, K., Choi, I., \& Norenzayan, A. (2001). Culture and systems of thought: Holistic versus analytic cognition. Psychological Review, 108(2), 291-310. https://doi.org/10.1037/0033-295x.108. 2.291

Norenzayan, A., Smith, E., Kim, B. \& Nisbett, R. (2002) Cultural preferences for formal versus intuitive 
reasoning. Cognitive Science, 26(5), 653-684. https://doi.org/10.1207/s15516709cog2605_4

Nosal, C. S. (1990). Psychologiczne modele umysłu. [Psychological models of the mind]. Warsaw: PWN.

Ooms, K., De Maeyer, P., Dupont, L., Van der Veken, N., Van de Weghe, N., \& Verplaetse, S. (2016). Education in cartography: What is the status of young people's map-reading skills? Cartography and Geographic Information Science, 43(2), 134153. https://doi.org/10.1080/15230406.2015 1021713

Opach, T., Popelka, S., Doležalová, J., \& Rød, J. K. (2018). Star and polyline glyphs in a grid plot and on a map display: Which perform better? Cartography and Geographic Information Science, 45(5), 400-419. https://doi.org/10.1080/15230406. 2017.1364169

Oyserman, D., \& Lee, S. (2008). Does culture influence what and how we think? Effects of priming individualism and collectivism. Psychological Bulletin, 134(2), 311-342. https://doi.org/10.1037/ 0033-2909.134.2.311

Oyserman, D., Coon, H., \& Kemmelmeier, M. (2002). Rethinking individualism and collectivism: Evaluation of theoretical assumptions and meta-analyses. Psychological Bulletin, 128(1), 3-72. https:/ /doi.org/10.1037/0033-2909.128.1.3

Peña, E. (2017). Mapping visual literacy [Doctoral Dissertation]. Vancouver: The University of British Columbia. http://doi.org/10.14288/1.0368982

Peterson, E., \& Deary, I. (2006). Examining the wholistic-analytic style using preferences in early information processing. Personality and Individual Differences, 41(1), 3-14. https://doi.org/10.1016/ j.paid.2005.12.010

Popelka, S., Stachoň, Z., Šašinka, Č., \& Doležalová, J. (2016). EyeTribe tracker data accuracy evaluation and its interconnection with Hypothesis software for cartographic purposes. Computational Intelligence and Neuroscience, 2016, 1-14. https:/ /doi.org/10.1155/2016/9172506

Robinson, A. (1952). The look of maps: An examination of cartographic design. Madison: University of Wisconsin Press.

Sadahiro, Y. (1997). Cluster perception in the distribution of point objects. Cartographica, 34(1), 4962. https://doi.org/10.3138/Y308-2422-8615-1233

Šašinka, Č., Morong, K., \& Stachoň, Z. (2017). The Hypothesis platform: An online tool for experimental research into work with maps and behavior in electronic environments. ISPRS International Journal of Geo-Information, 6(12), 1-22. https:// doi.org/10.3390/ijgi6120407

Šašinka, Č., Stachoň, Z., Kubíček, P., Tamm, S., Matas, A., \& Kukaňová, M. (2018). The Impact of global/ local bias on task-solving in map-related tasks employing extrinsic and intrinsic visualization of risk uncertainty maps. The Cartographic Journal, 55(4), 1-17. https://doi.org/10.1080/00087041. 2017.1414018

Singelis, T. (1994). The measurement of independent and interdependent self-construal. Personality and Social Psychology Bulletin, 20(5), 580591. https://doi.org/10.1177/0146167294205014

Slocum, T. A., McMaster, R. B., Kessler, F. C., \& Howard, H. H. (2005). Thematic cartography and geographic visualization. New Jersey: Pearson Prentice Hall.

Stachoň, Z., Šašinka, Č., Čeněk, J., Štěrba, Z., Angsuesser, S., Fabrikant, S., ... \& Morong, K. (2019). Cross-cultural differences in figure-ground perception of cartographic stimuli. Cartography and Geographic Information Science, 46(1), 82-94. https://doi.org/10.1080/15230406.2018.1470575

Stachoň, Z., Šašinka, Č., Čeněk, J., Angsüsser, S., Kubíček, P., Štěrba, Z., \& Bilíková. M., (2018). Effect of size, shape and map background in cartographic visualization: Experimental study on Czech and Chinese populations. ISPRS International Journal of Geo-Information, 7(427), 1-15. https:/ /doi.org/10.3390/ijgi7110427

Steele, L., \& Lynch, S. (2013). The pursuit of happiness in China: Individualism, collectivism, and subjective well-being during China's economic and social transformation. Social Indicators Research, 114(2), 441-451. https://doi.org/10.1007/s11205012-0154-1

Takano, Y., \& Osaka, E. (1999). An unsupported common view: Comparing Japan and the US on individualism/collectivism. Asian Journal of Social Psychology, 2(3), 311-341. https://doi.org/10.1111/ 1467-839X.00043

Takano, Y., \& Osaka, E. (2018). Comparing Japan and the United States on individualism/collectivism: A follow-up review. Asian Journal of Social Psychology, 21(4), 301-3016. https://doi.org/ 10.1111/ajsp.12322

Tan, Y. (2016). East-West cultural differencies in Visual Attention Tasks: Identifying multiple mechanism and developing a predictive model [Doctoral dissertation]. Michigan: Michigan Technological University. https://digitalcommons.mtu. edu/etdr/141

Triandis, H., \& Gelfand, M. (1998). Converging measurement of horizontal and vertical individualism and collectivism. Journal of Personality and Social Psychology, 74(1), 118-128. https://doi.org/ 10.1037/0022-3514.74.1.118

Tu, Y. K., Gunnell, D., \& Gilthorpe, M. S. (2008). Simpson's Paradox, Lord's Paradox, and Suppres- 
sion effects are the same phenomenon - the reversal paradox. Emerging Themes in Epidemiology, 5(2), 1-9. https://doi.org/10.1186/1742-76225-2

Tversky, B. (1981). Distortions in memory for maps. Cognitive Psychology, 13(3), 407-433. https:// doi.org/10.1016/0010-0285(81)90016-5

Uskul, A., Kitayama, S., \& Nisbett, R. (2008). Ecocultural basis of cognition: Farmers and fishermen are more holistic than herders. Proceedings of the National Academy of Sciences of the United States of America, 105(25), 8552-8556. https://doi.org/10.1073/pnas.0803874105

Varnum, M., Grossmann, I., Katunar, D., Nisbett, R., \& Kitayama, S. (2008). Holism in a European cultural context: Differences in cognitive style between Central and East Europeans and Westerners. Journal of Cognition and Culture, 8(3), 321333. https://doi.org/10.1163/156853708X358209

Vignoles, V., Owe, E., Becker, M., Smith, P., Easterbrook, M., Brown, R., ... \& Bond, M. (2016). Beyond the 'east-west' dichotomy: Global variation in cultural models of selfhood. Journal of Experimental Psychology: General, 145(8), 9661000. https://doi.org/10.1037/xge0000175 von Mühlenen, A., Bellaera, L., Singh, A., \& Srinivasa, N. (2018). The effect of sadness on global-local processing. Attention, Perception, \& Psychophysics, 80(5), 1072-1082. https://doi.org/10.3758/ s13414-018-1534-7

Wagemans, J., Elder, J., Kubovy, M., Pamer, M., Peterson, M., Sing, M., \& von der Heydt (2012). A Century of Gestalt psychology in visual perception: I. Perceptual grouping and figure-ground organization. Psychological Bulletin, 138(6), 11721217. https://doi.org/10.1037/a0029333

Witkin, H., Moore, C., Goodenough, D., \& Cox, P. (1977). Field dependent and field independent cognitive styles and their educational implications. Review of Educational Research, 47(1), 1-64. https://doi.org/10.3102/00346543047001001

Wood, D. (1984). Cultured symbols: Thoughts on the cultural context of cartographic symbols. Cartographica, 21(4), 9-37. https://doi.org/ 10.3138/B88T-68X3-L0J1-0226

Yates, J., Ji, L-J., Oka, T., Lee, J-W., Shinotsuka, H., \& Sieck, W. (2010). Indecisiveness and culture: Incidence, values, and thoroughness. Journal of Cross-cultural Psychology, 41(3), 428-444. https:/ /doi.org/10.1177/0022022109359692 